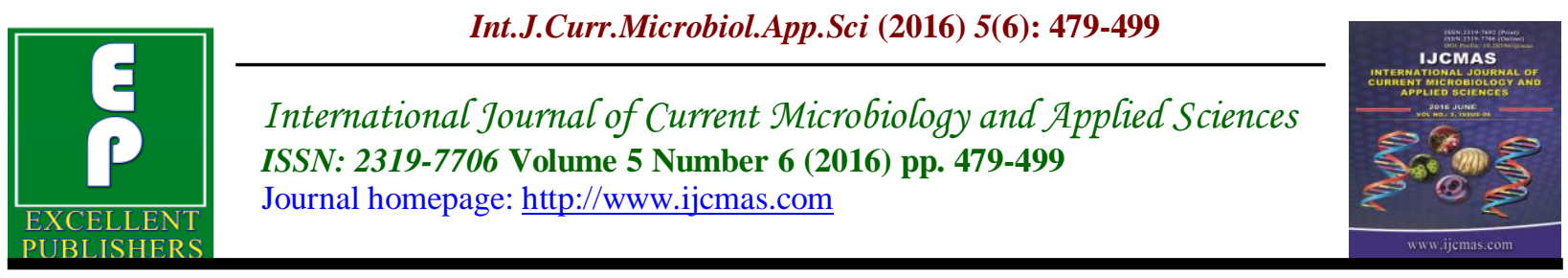

Original Research Article

http://dx.doi.org/10.20546/ijcmas.2016.506.055

\title{
Analysis of the Effect of Agitation and Aeration on Xylitol Production by Fermentation in Bioreactor with Kluyveromyces marxianus Using Hydrolized Tamarind Seed as Substrate
}

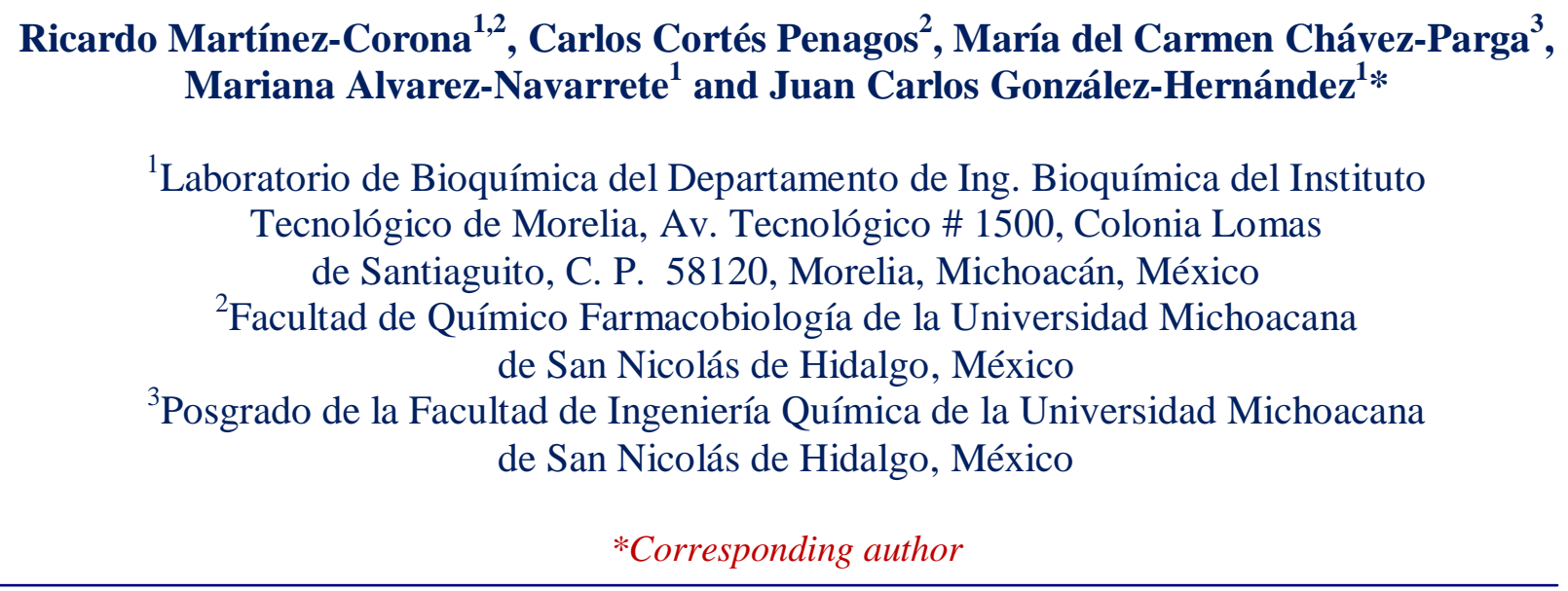

\begin{tabular}{|c|c|}
\hline & A B S T R A C T \\
\hline $\begin{array}{l}\text { Ke y w o r d s } \\
\text { Xylose, } \\
\text { Fermentation, } \\
\text { Xylitol, } \\
\text { Aeration, } \\
\text { Agitation. }\end{array}$ & \multirow{3}{*}{$\begin{array}{l}\text { Xylitol is a compound with high industrial value due to its chemical and physical } \\
\text { properties; at an industrial level, xylitol is produced by catalytic hydrogenation of } \\
\text { xylose, a process both costly and low-yield. As a viable alternative, xylitol can be } \\
\text { produced by fermentation with yeasts that use xylose as an energy source, such as } \\
\text { Kluyveromyces marxianus. As a substrate source we proposed the use of tamarind } \\
\text { seed, with high xylose content in its structure. Making use of xylose by yeast plus } \\
\text { the resulting xylitol, depend on various factors among which that of greatest impact } \\
\text { is the presence of oxygen in the fermentation medium. Therefore, in this study, the } \\
\text { effects of aeration and agitation on xylitol production using hydrolyzed tamarind } \\
\text { seed as a substrate medium were evaluated, employing a } 2^{2} \text { factorial experimental } \\
\text { design with a central point. In this way, aeration and interaction of the factors (both } \\
\text { aeration and agitation) were the ones which had a significant effect on xylitol } \\
\text { production. The highest yield reached was of } 0.71 \mathrm{~g} \text { of xylitol/g of xylose with } \\
\text { agitation at } 100 \mathrm{rpm} \text { and, aeration at } 0.1 \mathrm{vvm} \text { in semi anaerobic conditions. }\end{array}$} \\
\hline Article Info & \\
\hline $\begin{array}{l}\text { Accepted: } \\
\text { 20 May } 2016 \\
\text { Available Online: } \\
\text { 10 June } 2016\end{array}$ & \\
\hline
\end{tabular}

\section{Introduction}

Xylitol is industrially produced by catalytic hydrogenation at both high pressure and temperature, using commercial xylose or some similar organic source with high content of this monosaccharide; in said process, due to exhaustive purification stages in an effort to obtain high purity xylose, this proved to be both expensive and of low-yield (Gaström, 2002; Vanegas et al., 2004). Xylitol is a carbohydrate similar in appearance and sweetness to sucrose; it is suitable for use as a food sweetener for 
diabetics, as its metabolism is not regulated by insulin (Arrizon et al., 2011). Xylitol remains stable in food preparation, neither fermenting nor producing Maillard browning (Silva and Roberto, 2001); is it proved to have advantages regarding health as although a sweetener it does not provoke caries as it cannot be utilized or fermented by bacteria present in the oral cavity (Bahador et al., 2012). Xylitol is an attractive ingredient in tablets, cough mixtures, mouth-washes, tooth-paste, etc. (Ahmed, 2001).

Xylitol can also be produced by fermentation of yeasts which use xylose as an energy source (Ghindea et al., 2010). The first metabolic step in the fermentation of xylose corresponds to its transport to the yeast cytoplasm. Xylose is introduced into the cell through glucose transporters, which are permeases in the cell membrane that carry sugars by facilitated diffusion (Boris et al., 2003). Alternatively, non-conventional yeast possesses a xylose symporter which permits its passage through the abovementioned by facilitated diffusion due to the motor force generated by a proton-ATPase (Weusthuis and Pronk, 1994).

Once inside the cytoplasm, the xylose is introduced into the yeast metabolism in three stages; first, xylose is reduced to xylitol by D-xylose reductase (XR) using $\mathrm{NADH}$ or NADPH as cofactor. Depending on the environmental conditions, xylitol is released from the cell or oxidized to xylulose by xylitol dehydrogenase $(\mathrm{XDH})$ in the presence of $\mathrm{NAD}^{+}$. The xylulose is then phosphorylated by a xylulokinase with consumption of ATP, so as to be incorporated in the pentose phosphate pathway (PPP) and finally to glycolysis (Garström, 2002).

Xylitol production by fermentation depends on various factors, such as: oxygen conditions in the medium, size of the inoculum, substrate concentration and composition of the medium, temperature and $\mathrm{pH}$; of these, the one with the most impact is the presence of oxygen. At low oxygen concentration in the culture medium the electron transference system is incapable to reoxidaze all the NADH produced, with a consequent increase in the latter and a decrease in xylitol to xylulose oxidation step, and finally, a considerable accumulation of xylitol (Does and Bisson, 1989; Deok-Kun et al., 1997; Martinez et al., 2002). However, there is a lack of information on the parameters that directly affect the oxygen concentration in a culture medium: agitation and aeration.

The biotechnological production of xylitol is of economic, academic and scientific interest when it is obtained from low-cost readily available raw material. Various studies have been carried out for producing xylitol, using residues of high xylose content, to mention a few: hydrolyzed eucalyptus and wheat straw (Martinez et al., 2002), hydrolyzed rice straw (Roberto et al., 1999), hydrolyzed sugar cane (Santos et al., 2003), barley malt residue (Solange and Inés, 2005), corn cob with added xylose (Latina et al., 2006) and rice husk (Villalba et al., 2009).

The use of a hydrolyzed medium of tamarind seed for xylitol production has not been reported. Tamarind seed consists of a high percentage of carbohydrate (50 to 72 $\%$ ) (El-Sidding et al., 2006), which is found as a ramified heteropolysaccharide, known as xyloglucan, principally composed of Dglucose, D-xylose, D-galactose and Larabinose in proportions 8: 4: 2: 1, respectively (Kauer and Kauer, 2006). Due to its high xylose content, tamarind seed is a potential substrate source with regard to xylitol-producing yeasts (GonzálezHernández et al., 2012). As Saucedo-Luna 
et al., described, the production of alcohols derived from a fermentation process from organic residues takes place in three stages: hydrolysis of the polysaccharide to form monosaccharides, fermentation of sugars by yeast or bacteria to alcohol products and finally, the purification of the aforementioned. Currently hydrolysis is carried out in either concentrated acid environment or in presence of enzymes.

In this study, we have evaluated the effect of aeration and agitation on xylitol production by fermentation in a bioreactor of hydrolyzed tamarind seed media using $K$. marxianus, of which yeast specie very little has been written in relation to its potential in the production of this interesting compound.

\section{Materials and Methods}

\section{Experimental Design}

The effect of two factors (aeration and agitation) which are key in yeast growth, yield and production of xylitol, was evaluated by means of a factorial $2^{2}$ experimental design with a central point. Codified levels for each factor, the resultant four factorial treatments, plus the central point are shown in Table 1. Each treatment of the randomized experimental design was performed for duplicate, for statistical analysis purposes. The planning of the experimental design and the obtaining of the fully randomized treatments was performed with Stathgraphics Centurion XV® software.

\section{Hydrolyzed Tamarind Seed Media}

Following the hydrolysis steps established by González-Hernández et al., tamarind seed powder with a maximum diameter of $0.125 \mathrm{~mm}$, was transferred to acid hydrolysis by diluting with nitric acid $3 \%$ and heat treatment by autoclave at $121{ }^{\circ} \mathrm{C}$, for 20 minutes. Said powder had been previously obtained from ground and sieved tamarind seed grain. Centrifugation at 4000 rpm for 15 minutes and filtration were used in order to remove the solid fraction of the hydrolyzed medium.

\section{Microorganism and preparation of inoculum}

The yeast employed in fermentation tests, Kluyveromyces marxianus ITMLB03, was grown in Petri plates with a medium of YPD-hydrolyzed tamarind seed $(10 \mathrm{~g} / \mathrm{L}$ glucose, $10 \mathrm{~g} / \mathrm{L}$ sugars of hydrolyzed tamarind seed, $10 \mathrm{~g} / \mathrm{L}$ bactopeptone, $10 \mathrm{~g} / \mathrm{L}$ yeast extract, $10 \mathrm{~g} / \mathrm{L}$ agar) and stored in refrigeration. The stored yeast was transferred by bacteriological loop to 100 $\mathrm{mL}$ of fermentation medium (hydrolyzed tamarind seed) in a $250 \mathrm{~mL}$ Erlenmeyer flask for the preparation of the inoculum, then incubated at $30{ }^{\circ} \mathrm{C}$ for $24 \mathrm{~h}$ and shaken at $180 \mathrm{rpm}$.

\section{Fermentation Tests}

Fermentation tests based on the different treatments in the experimental design were performed in a bioreactor at a constant temperature of $30{ }^{\circ} \mathrm{C}$ and an initial $\mathrm{pH}$ of approximately 6.3 , which was adjusted in the tamarind seed media with a tris $\mathrm{NH}_{2} \mathrm{C}\left(\mathrm{CH}_{2} \mathrm{OH}\right)_{3} 2 \mathrm{M}$ solution and was not controlled during tests. The initial substrate concentration (corresponding to the content of reducing sugars) was adjusted by diluting with distilled water at $50 \mathrm{~g} / \mathrm{L}$, in accordance with Martínez-Corona et al., As a nitrogen source for the yeasts, ammonium phosphate $\left(\mathrm{NH}_{4}\right)_{2} \mathrm{H}_{2} \mathrm{PO}_{4}$ was added, in a proportion of $1 \mathrm{~g} / \mathrm{L}$.

The bioreactor employed was an Applikon ${ }^{\circledR}, 3 \mathrm{~L}$ volume, $0.13 \mathrm{~m}$ diameter, 
with two Rushton 6-blades agitator, 3 deflectors and a perforated-tube air distributor type L. This equipment was sterilized for each treatment of the experimental design, containing a medium culture (hydrolyzed tamarind seed) volume of $1.7 \mathrm{~L}$, autoclaved at $121{ }^{\circ} \mathrm{C}, 1 \mathrm{~atm}$, for 15 min. In this way, the hoses (for sample extraction and aeration) together with all the necessary material for the fermentation tests were sterilized.

A concentration of $3 \times 10^{6}$ cells $/ \mathrm{mL}$ of $K$. marxianus was inoculated for each treatment. The agitator plus the $\mathrm{pH}$ and the dissolved oxygen sensors were disinfected using ethanol and connected to the biocontroller. As previously mentioned, the temperature was maintained at a constant of $30{ }^{\circ} \mathrm{C}$, by means of a water bath with a Science Temperature Controller®.

Aeration was controlled using an Aalborg Rotameter® connected to a compressor. The flow $(\mathrm{L} / \mathrm{min})$ needed to establish the various levels with regard to the aeration factor, based on the volume of the culture medium in the bioreactor, are shown in Table 2.

Samples were taken every $12 \mathrm{~h}$, which in turn demonstrated doubling time of the yeast $\left(t_{d}\right)$, substrate consumption (glucose and xylose) and product generation (xylitol, ethanol and glycerol), resulting in the conversion factor of xylose to xylitol $\left(\mathrm{Y}_{\mathrm{p} / \mathrm{s}}\right)$.

\section{Analytical Methods}

Concentration of reducing sugars from the hydrolyzed tamarind seed media was measured using the oxide-reduction technique of the DNS ( Pérez et al., 2013). In the presence of reducing sugars, the 3,5dinitrosalicylic acid reduces to 3-amino-5nitrosalicylic acid, provoking a color change which is quantified by absorbance at a wave-length of $540 \mathrm{~nm}$.
Concentrations of glucose and xylose, the main sugars in the hydrolyzed medium and substrates for the yeast during fermentation, were calculated by enzyme tests using Megazyme ${ }^{\circledR}$ kits: for glucose, the one used for catalyzed reactions of glucosidase and peroxidase, and for xylose, those catalyzed by xylose dehydrogenase, both with a resultant change in absorbance of the sample measured in a UV-Visible JENWAY 6305® spectrophotometer. The measurement of furfurals was carried out according to the methodology proposed by Martínez et al., The furfural, together with the hydroximethyl furfural, shows a combined absorbance peak in the UV spectrum at 284 $\mathrm{nm}$. The absorbance of some other compounds present in the hydrolyzed media of organic residue is observed in the same region, but maintains an absorbance code at $320 \mathrm{~nm}$. By subtracting both absorbances and comparing with a standard curve, it can be measured the concentration of these compounds in the hydrolyzed tamarind seed media.

The main fermentation products were quantified by using enzyme assays with Megazyme® kits: for xylitol (regarding catalyzed reactions by xylitol dehydrogenase and diaphorase), ethanol (with alcohol dehydrogenase and aldehyde dehydrogenase) as described by Pérez et al., and glycerol (with enzymes glyceroquinase and lactate dehydrogenase), with a resultant change in absorbance of the sample measured in a UV-Visible JENWAY 6305® spectrophotometer.

\section{Statistical Analysis}

Analysis of the results was carried out on Statgraphics Centurion XV® software for three response variables of the experimental design: doubling time $\left(\mathrm{t}_{\mathrm{d}}\right)$, product-substrate yield $\left(\mathrm{Y}_{\mathrm{p} / \mathrm{s}}\right)$ and xylitol production. Furthermore, a Tukey-Kramer test was 
applied for the above-mentioned was realized on said response variables together with the ethanol and glycerol production, using JMP 6.0® software.

\section{Results and Discussion}

The average composition of those fermentation media used in distinct treatments of the experimental design (at bioreactor level) are shown in Table 3. The initial substrate concentration for all fermentations was of $50 \mathrm{~g} / \mathrm{L}$, according to the results reported previously (MartinezCorona et al., 2015).

Hydrolyzed tamarind seed prepared in the conditions established by GonzálezHernández et al., and adjusted to $50 \mathrm{~g} / \mathrm{L}$ reducing sugars (Saucedo-Luna et al., 2010) showed a higher glucose concentration $(23.802 \mathrm{~g} / \mathrm{L})$ compared to that reported by Martínez et al., for other hemicellulosic hydrolysates: sugar cane bagasse $(1.70 \mathrm{~g} / \mathrm{L})$, rice straw (3.29 g/L), eucalyptus (1.53) and wheat straw $(2.79 \mathrm{~g} / \mathrm{L})$. As for the xylose concentration in hydrolyzed tamarind seed (shown in Table 3) this is seen to be slightly higher than that reported by MartínezCorona et al., for the same substrate prepared in similar conditions and adjusted to the self-same concentration of reducing sugars, being $11.621 \mathrm{~g} / \mathrm{L}$. Despite this factor, the xylose concentration is lower than that obtained by Kiyoshi et al., who also used Candida magnoliae in fermentation of hydrolyzed corncob, of approximately 25 $\mathrm{g} / \mathrm{L}$.

The acid and thermal conditions in which hydrolysis is carried out, generate compounds (such as acetic acid, phenolic derivatives, furfural and hydroximethylfurfural) that are capable of both limiting and obstructing xylitol production (Fernández et al., 2007). Of these, the most important are the furfurals, which are originated from the Maillard reactions regarding pentose and hexose during the acid hydrolysis; the furfural results from the pentose dehydration while the hydroximethylfurfural from that of xylose (Palmqvist and Hanh-Hägerdal, 2000). Although the precise mechanism by which the furfurals inhibit yeast metabolism is not known, it has been suggested that these compounds inhibit the central enzymes of glycolysis (such as hexoquinase and phosphofructoquinase) or enzymes related to either the citric acid cycle or ethanol production (alcohol dehydrogenase and aldehyde dehydrogenase) (Almeida et al., 2007). What is more, it has been reported that yeasts not only use but also transform furfurals into furfuryl alcohol and furoic acid under anaerobic conditions (Winkelhausen et al., 2004).

Furfural concentration in the hydrolyzed tamarind seed media (adjusted to $50 \mathrm{~g} / \mathrm{L}$ ) was of $0.214 \mathrm{~g} / \mathrm{L}$ (Table 3), being slightly higher than that reported by Martínez et al., for hydrolyzed sugar cane bagasse (0.19 $\mathrm{g} / \mathrm{L})$, but lower than that obtained by the same authors for hydrolyzed rice straw $(0.27$ $\mathrm{g} / \mathrm{L})$, eucalyptus wood $(0.64 \mathrm{~g} / \mathrm{L})$ and wheat straw $\quad(0.43 \mathrm{~g} / \mathrm{L})$. However, said concentration of furfurals found in the hydrolyzed tamarind seed media did not affect yeast growth, as a lethal inhibition was not observed in any of the treatments of the experimental design.

\section{Cell Growth}

Growth and adaptation of $K$. marxianus in bioreactor fermentation tests are analyzed based on doubling time $\left(t_{d}\right)$ calculated from growth kinetics in the different treatments (data not shown). Doubling time is demonstrated and statistically compared in Table 4. 
According to the variance analysis regarding the doubling time response variable, the two main factors (agitation and aeration) do not have any significant effect on said variable. Factor interaction is significant on a confidence level of $95 \%$ (Table 5). The lowest doubling times were encountered at the highest level of both factors, as can be seen in Figure 1A. However, the principal effect showed on this response variable was due to interaction of both factors, thereby demonstrating its significance in variance analysis. Therefore, the lowest doubling times are found in a low agitation level (100 rpm) combined with a high aeration one (1 vvm), and in a high agitation level (200 $\mathrm{rpm})$ combined with a low aeration one $(0.1$ vvm), as seen in Figure 1B.

The doubling times of treatments 2 and 3, resulted statistically lower according to the Tukey-Kramer test (Table 4). The yeast growth in which the conditions have the greatest impact were at an agitation of 100 rpm and at an aeration of 0.1 vvm, expanding the exponential growth phase and, therefore, increasing the doubling time response variable $(4.521 \mathrm{~h})$.

\section{Xylose Consumption and Xylitol Production}

Xylose consumption was different for the two treatments at a low agitation level (100 $\mathrm{rpm}$ ), at a high aeration level (1 vvm; treatment 5) and at a low one (0.1 vvm; treatment 3), as shown in Figure 2A. In treatment 5, little use was made of the xylose available in the fermentation medium, having a final xylose uptake of only $46 \%$. On the other hand, in treatment 3 accelerated substrate consumption was observed from 36 to $48 \mathrm{~h}$ of fermentation, exhausting a sum-total of $70 \%$ xylose. It was this latter treatment which produced most xylitol at the end of fermentation kinetics, reaching a product average of 5.1 $\mathrm{g} / \mathrm{L}$ (Figure 3A).

At a high agitation level (200 rpm) xylose consumption was also benefited by a high aeration level (1 vvm), reaching $79 \%$ consumption, with reference to treatment 2 (aeration of $0.1 \mathrm{vvm}$ ) where only $58 \%$ of available xylose was consumed (Figure 2B). This fact was reflected in xylitol production where product concentration of $3.43 \mathrm{~g} / \mathrm{L}$ was reached in treatment 1 , whereas $2.58 \mathrm{~g} / \mathrm{L}$ in treatment 2 (Figure 3B). The lowest consumption of xylose $(45 \%)$ occurred in treatment 4 , at the central points of both factors (Figure 2B).

The product-substrate yield $\left(\mathrm{Y}_{\mathrm{p} / \mathrm{s}}\right)$ and productivity were calculated from the xylose consumption and xylitol production data, and are statistically compared in Table 4.

Although no significant effect of the agitation and aeration on product-substrate yield $\left(\mathrm{Y}_{\mathrm{p} / \mathrm{s}}\right)$ was shown in the variance analysis (Table 6), minor lineal effects of both factors can be observed in Figure 4A, where a better yield would be expected at low agitation levels (100 rpm) and at low aeration ones $(0.1 \mathrm{vvm})$.

Product-substrate yield (Table 6) was affected when a high aeration level (1 vvm) was employed. At a low aeration level (0.1 vvm) combined with a high agitation level (200 rpm) the lowest yield was obtained (Figure 4B). As was to be expected, when a low agitation level for aeration at $0.01 \mathrm{vvm}$ was used, the yield considerably increased and it is precisely on this point where the best results according to the experimental design, were achieved.

The value obtained at said levels $(0.7092 \mathrm{~g}$ of $x y l i t o l / g$ of xylose), using the TukeyKramer test, is statistically higher than that 
of other treatments of the experimental design (Table 4). Although a high yield was not expected in treatment 1 (at $200 \mathrm{rpm}$ and $1 \mathrm{vvm}$ ) it turned out to be the second highest.

Maximum xylitol productivity $(0.106 \mathrm{~g} / \mathrm{L} \mathrm{h})$ was reached in treatment 3 after $48 \mathrm{~h}$ of incubation, although no statistical significant difference was found in relation with the other treatments (Table 4). However, no relation was found between the productsubstrate yield parameter and xylitol productivity: at the highest yield (in treatment 5) the lowest productivity was observed.

The presence of oxygen in the culture medium is one of the studied-factors which most affect xylitol production in a fermentation process. Metabolically, in limited oxygen conditions, an accumulation of NADH is produced (generated during the oxidation of xylitol to xylose and limiting this reaction) with subsequent xylitol accumulation (Deok-Kun et al., 1997).

It was precisely the aeration factor which had a significant effect on the xylitol production at the end of the fermentation, as shown in the variance analysis for this response variable in Table 7 . Nevertheless, the effect of this factor was not that expected, but quite the opposite. Xylitol production was seen to be affected at a low level of $0.1 \mathrm{vvm}$, whereas it was benefited from $1 \mathrm{vvm}$ (Figure 5A).

It has been reported that xylose metabolism, in yeasts such as $K$. marxianus, would not appear to be limited by its transportation from extracellular medium to cytoplasm. However, the transportation of xylose through the cellular membrane could limit its use in aerobic and semianaerobic conditions (Winkelhausen et al., 2004).
In limited oxygen conditions, and xylose being the only substrate, xylose is reduced to xylitol, but cannot be oxidized to xylose so as to be incorporated to the phosphate pentose pathway (PPP), of which the end result is the generation of pyruvate (Figure 5). Combined with the accumulation of xylitol and $\mathrm{NADH}$, this translates into a nil production of ATP (because of its inhibiting effect on the respiration chain) which is of vital importance in the transportation of the monosaccharide (xylose) from the extracellular medium to the yeast cytoplasm (2001). Therefore, semianaerobic conditions are necessary for xylitol production, finding an improved balance in this study at an aeration of $1 \mathrm{vvm}$.

Although it did not have a significant effect on the xylitol production response variable (Table 7), a slight effect of the agitation factor can be observed (Figure 5A). An increase of the testing range of agitation could contribute to distinguish if a significant effect of this factor does, in fact, exist. In comparing interaction effects, higher xylitol production can be observed with low-level agitation again (Figure 5B).

In spite of the fact that treatment 3 had the highest production of xylitol, this did not differ, statistically speaking, from the other treatments of the experimental design (compared using the Tukey-Kramer test in Table 4), owing to the variability of the results obtained from the repetition of the fermentation tests.

As has been already mentioned, the highest yield reached in treatments at bioreactor level with $K$. marxianus, were at low agitation (100 rpm) and aeration levels (0.1 $\mathrm{vvm}$ ), being $0.71 \mathrm{~g}$ of xylitol/g of xylose. This value is much more than that obtained by Wannawilai et al., (2007) who employed C. magnoliae in a bioreactor (fermentation 
volume of $1 \mathrm{~L}$ ), in a synthetic fermentation medium of xylose, which resulted in $0.39 \mathrm{~g}$ of xylitol/g of xylose; furthermore, it is higher than that obtain by Furlan and de Castro (2001), using C. parapsilosis in fermentation at bioreactor level with mixed synthetic medium which was $0.63 \mathrm{~g}$ of xylitol/g of xylose.

One of the highest yields obtained at bioreactor level for xylitol production, was that attributed to Ojamo et al., (1994) which was of $0.78 \mathrm{~g}$ of xylitol/g of xylose by fermentation in a synthetic medium of xylose, using $C$. guilliermondii. There have also been reports of high yields based on fermentation from different sources of hemicellulosic hydrolysates using $C$. guilliermondii at bioreactor level: Roberto et al., (1999) reached a yield of $0.73 \mathrm{~g}$ of xylitol/g of xylose, employing rice straw as hydrolyzed substrate medium; while for their part, Acosta et al., (2005) reported a yield of $0.75 \mathrm{~g}$ of xylitol/g of xylose by fermentation of hydrolyzed sugar cane bagasse. In our study, the yield reached does not differ all that much from the abovementioned reports with a widely-used yeast employed for xylitol production, namely $C$. guilliermondii, at bioreactor level, proposing $K$. marxianus as a yeast with acceptable yields in xylitol production.

\section{Glucose Consumption and Ethanol Production}

No significant differences were observed with respect to glucose consumption in the 5 treatments of the experimental design (Figure 6). In all cases, consumption of this substrate was accelerated during first $24 \mathrm{~h}$ of fermentation, followed by a period of deceleration (under $5 \mathrm{~g} / \mathrm{L}$ ). Total yeast consumption of available glucose in the different treatments was between 92 and 94 $\%$.
With agitation at 100 rpm, ethanol production increased during the initial hours of fermentation at both levels of aeration (Figure 7A). Of these two treatments, the one at aeration of $0.1 \mathrm{vvm}$ was that which showed higher product generation, which was maintained at a constant as from approximately $24 \mathrm{~h}$. At a high aeration level (treatment 3), there were slight variations as from $12 \mathrm{~h}$, reaching maximum concentration at the end of fermentation.

At a high agitation level, treatments 1 and 2 showed a similar ethanol production after 80 $h$ of fermentation. On the other hand, at a low agitation level, the highest production occurred during the initial hours (Figure

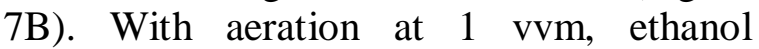
concentration maintained constant during the remainder of the kinetic; while a low aeration level $(0.1 \mathrm{vvm})$ showed a maximum at $36 \mathrm{~h}$. Contrasting with the aforementioned treatments, in the central point the greatest production of ethanol occurred at $24 \mathrm{~h}$ of fermentation (Figure 7B).

Tendencies observed in Figure 7, where the highest production of ethanol in all the treatments of the experimental design occurred in the first hours of fermentation, would suggest that ethanol production is principally linked to the exponential growth phase of the yeast (data not shown) and, consequently, to glucose consumption in the fermentation medium. However, xylose uptake and metabolism could improve ethanol production in any growth phase.

Xylose consumption together with xylitol production during the stationary phase, limit ethanol production, for which reason the concentration of said product is maintained at a constant during the mentioned growth stage of $K$. marxianus. 
Table.1 Treatments and coded values for the factorial 22 experimental design with a central point.

\begin{tabular}{ccccc}
\hline & & & \multicolumn{2}{c}{ Coded values } \\
\cline { 4 - 5 } Treatment & $\begin{array}{c}\text { Agitation } \\
(\mathbf{r p m})\end{array}$ & $\begin{array}{c}\text { Aeration } \\
(\mathbf{v v m})\end{array}$ & $\mathbf{A}$ & $\mathbf{B}$ \\
\cline { 4 - 5 } & 200 & 1 & 1 & 1 \\
2 & 100 & 1 & -1 & 1 \\
3 & 200 & 0.1 & 1 & -1 \\
4 & 150 & 0.55 & 0 & 0 \\
5 & 100 & 0.1 & -1 & -1 \\
\hline
\end{tabular}

Table.2 Air flow in the rotameter for each level of the factorial 22 experimental design with a central point.

\begin{tabular}{ccc}
\hline Aeration $(\mathbf{v v m})$ & Coded value & Air flow (L/min) \\
\hline 0.1 & -1 & 0.17 \\
0.55 & 0 & 0.935 \\
1 & 1 & 1.7 \\
\hline
\end{tabular}

Table.3 Composition of the hydrolyzed tamarind seed media for the treatments of the factorial 22 experimental design with a central point.

\begin{tabular}{cccc}
\hline $\begin{array}{c}\text { Initial substrate } \\
\text { concentration }(\mathbf{g} / \mathbf{L})\end{array}$ & Glucose $(\mathbf{g} / \mathbf{L})$ & Xylose (g/L) & Furfurals (g/L) \\
\hline 50 & $23.802 \pm 3.398$ & $12.795 \pm 0.905$ & $0.214 \pm 0.014$ \\
\hline
\end{tabular}

The data show the mean \pm standard deviation for $n=10$

Table.4 Average results of factorial 22 experimental design with a central point, for different parameters compared by Tukey-Kramer statistical test.

\begin{tabular}{ccccccccc}
\hline $\begin{array}{c}\text { Treat } \\
\text { ment }\end{array}$ & $\begin{array}{c}\text { Factor } \\
\mathbf{A}\end{array}$ & $\begin{array}{c}\text { Factor } \\
\mathbf{B}\end{array}$ & $\begin{array}{c}\mathbf{Y}_{\mathbf{p} / \mathbf{s}}(\mathbf{g} \\
\mathbf{x y l i t o l} / \mathbf{g} \\
\mathbf{x y l o s e})\end{array}$ & $\mathbf{t}_{\mathbf{d}} \mathbf{( h )}$ & $\begin{array}{c}\text { Xylitol } \\
(\mathbf{g} / \mathbf{L})\end{array}$ & $\begin{array}{c}\text { Xylitol } \\
\text { productivity } \\
(\mathbf{g} / \mathbf{L} \mathbf{~ h})\end{array}$ & $\begin{array}{c}\text { Ethanol } \\
(\mathbf{g} / \mathbf{L})\end{array}$ & $\begin{array}{c}\text { Glycerol } \\
(\mathbf{g} / \mathbf{L})\end{array}$ \\
\hline 1 & 1 & 1 & $0.5609^{\mathrm{B}}$ & $3.648^{\mathrm{AB}}$ & $3.675^{\mathrm{A}}$ & $0.077^{\mathrm{A}}$ & $13.442^{\mathrm{B}}$ & $1.627^{\mathrm{B}}$ \\
2 & -1 & 1 & $0.4491^{\mathrm{C}}$ & $2.563^{\mathrm{BC}}$ & $2.579^{\mathrm{A}}$ & $0.054^{\mathrm{A}}$ & $12.366^{\mathrm{B}}$ & $3.79^{\mathrm{A}}$ \\
3 & 1 & -1 & $0.4805^{\mathrm{BC}}$ & $2.337^{\mathrm{C}}$ & $5.101^{\mathrm{A}}$ & $0.106^{\mathrm{A}}$ & $15.270^{\mathrm{B}}$ & $1.834^{\mathrm{B}}$ \\
4 & 0 & 0 & $0.3931^{\mathrm{C}}$ & $3.702^{\mathrm{AB}}$ & $2.566^{\mathrm{A}}$ & $0.053^{\mathrm{A}}$ & $14.152^{\mathrm{B}}$ & $2.011^{\mathrm{B}}$ \\
5 & -1 & -1 & $0.7092^{\mathrm{A}}$ & $4.521^{\mathrm{A}}$ & $2.378^{\mathrm{A}}$ & $0.050^{\mathrm{A}}$ & $21.538^{\mathrm{A}}$ & $2.78^{\mathrm{AB}}$ \\
\hline
\end{tabular}

Means followed by the same letter do not differ at a significance level $\alpha=0.05$. Table representative for $n=2$ 
Table.5 ANOVA for the doubling time $(\mathrm{td})$ response variable

\begin{tabular}{cccccc}
\hline $\begin{array}{c}\text { Source of } \\
\text { variation }\end{array}$ & $\begin{array}{c}\text { Sum of } \\
\text { Squares (SS) }\end{array}$ & $\begin{array}{c}\text { Degrees of } \\
\text { Freedom } \\
(\mathbf{d f})\end{array}$ & $\begin{array}{c}\text { Mean Square } \\
\text { (MS) }\end{array}$ & F-value & P-value \\
\hline A:Agitation & 0.20924 & 1 & 0.20924 & 1.64 & 0.2481 \\
B:Aeration & 0.603022 & 1 & 0.603022 & 4.72 & 0.0729 \\
AB & 5.34383 & 1 & 5.34383 & 41.79 & 0.0006 \\
Error & 0.767207 & 6 & 0.127868 & & \\
Total & 6.9233 & 9 & & & \\
\hline
\end{tabular}

The null hypothesis are rejected when the P-value is less than the established significance level $(\alpha=0.05)$

Table.6 ANOVA for the product-substrate yield (Yp/s) response variable

\begin{tabular}{cccccc}
\hline $\begin{array}{c}\text { Source of } \\
\text { variation }\end{array}$ & $\begin{array}{c}\text { Sum of } \\
\text { Squares (SS) }\end{array}$ & $\begin{array}{c}\text { Degrees of } \\
\text { Freedom }(\mathbf{d f})\end{array}$ & $\begin{array}{c}\text { Mean } \\
\text { Square } \\
\text { (MS) }\end{array}$ & F-value & P-value \\
\hline A:Agitation & 0.0161666 & 1 & 0.0161666 & 1.91 & 0.2161 \\
B:Aeration & 0.00683732 & 1 & 0.00683732 & 0.81 & 0.4032 \\
AB & 0.0579722 & 1 & 0.0579722 & 6.85 & 0.0397 \\
Error & 0.0507482 & 6 & 0.00845804 & & \\
Total & 0.131724 & 9 & & & \\
\hline
\end{tabular}

The null hypothesis are rejected when the P-value is less than the established significance level $(\alpha=0.05)$

Table.7 ANOVA for the xylitol production response variable

\begin{tabular}{cccccc}
\hline $\begin{array}{c}\text { Source of } \\
\text { variation }\end{array}$ & $\begin{array}{c}\text { Sum of } \\
\text { Squares (SS) }\end{array}$ & $\begin{array}{c}\text { Degrees of } \\
\text { Freedom } \\
(\mathbf{d f})\end{array}$ & $\begin{array}{c}\text { Mean Square } \\
\text { (MS) }\end{array}$ & F-value & P-value \\
\hline A:Agitation & 0.750068 & 1 & 0.750068 & 0.97 & 0.3637 \\
B:Aeration & 7.28894 & 1 & 7.28894 & 9.38 & 0.0221 \\
AB & 1.32243 & 1 & 1.32243 & 1.7 & 0.2398 \\
Error & 4.66054 & 6 & 0.776757 & & \\
Total & 14.022 & 9 & & & \\
\hline \multicolumn{7}{l}{ The null hypothesis are rejected when the P-value is less than the established significance level $(\alpha=0.05)$}
\end{tabular}


Fig.1 Effects of the aeration and agitation on the doubling time (td): (A) Principal effects of the factors and (B) interaction effect.

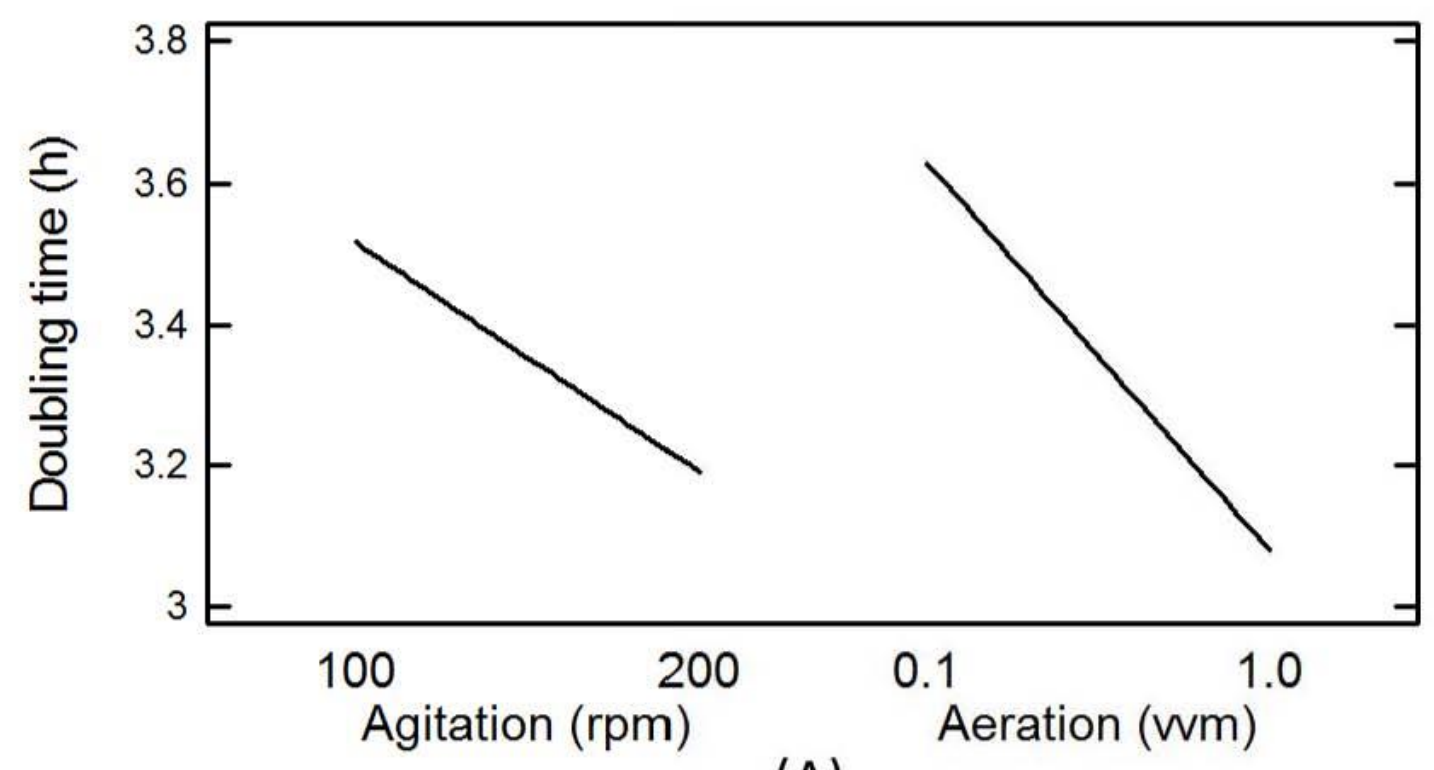

(A)

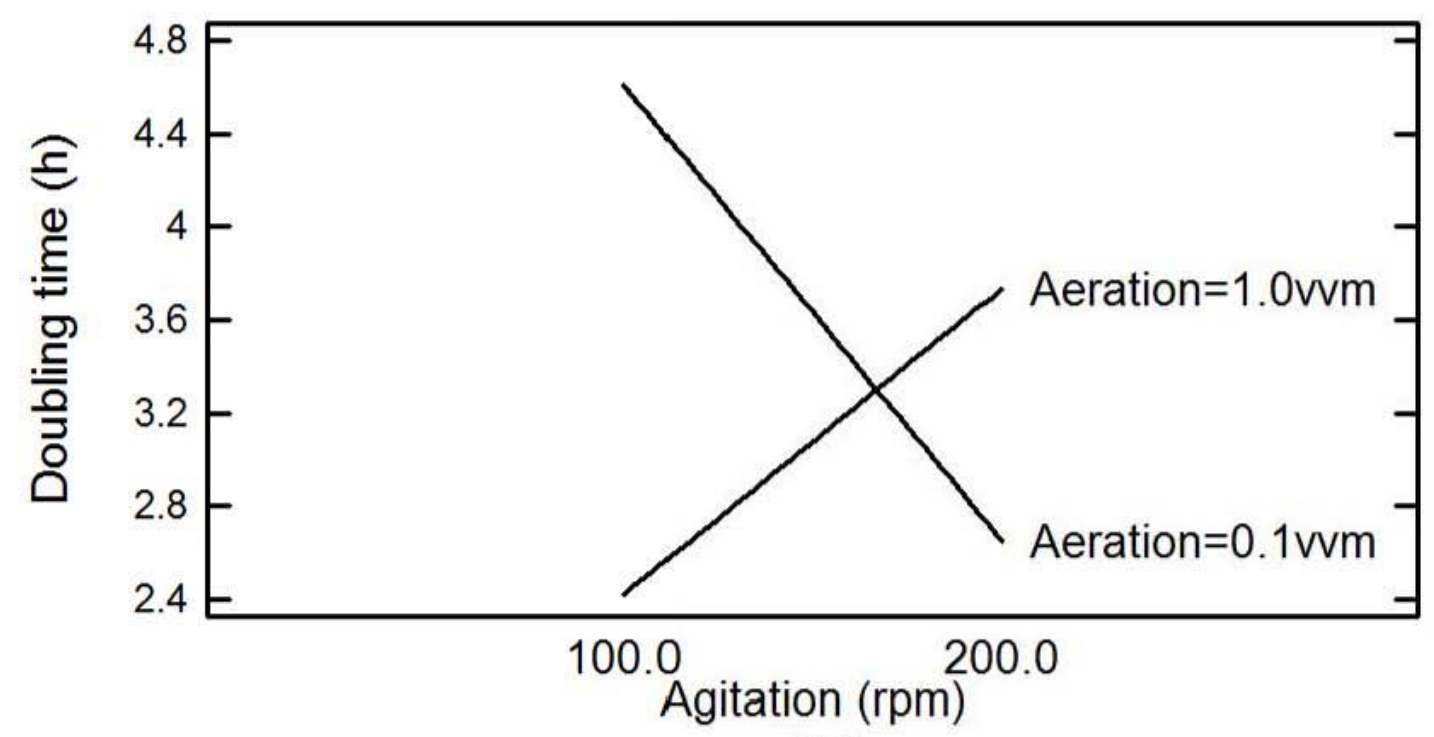

(B) 
Fig.2 Xylose consumption on the treatments of the factorial 22 experimental design with a central point. (A) Agitation of $100 \mathrm{rpm}$ and aeration of ( $0.1 \mathrm{vvm},(\bullet) 1 \mathrm{vvm}$; (B) Agitation of $200 \mathrm{rpm}$ and aeration of (ム) $0.1 \mathrm{vvm},(\diamond) 1 \mathrm{vvm}$ and $(ж) 0.55 \mathrm{vvm}, 150 \mathrm{rpm}$. Representative data for $\mathrm{n}=2$.

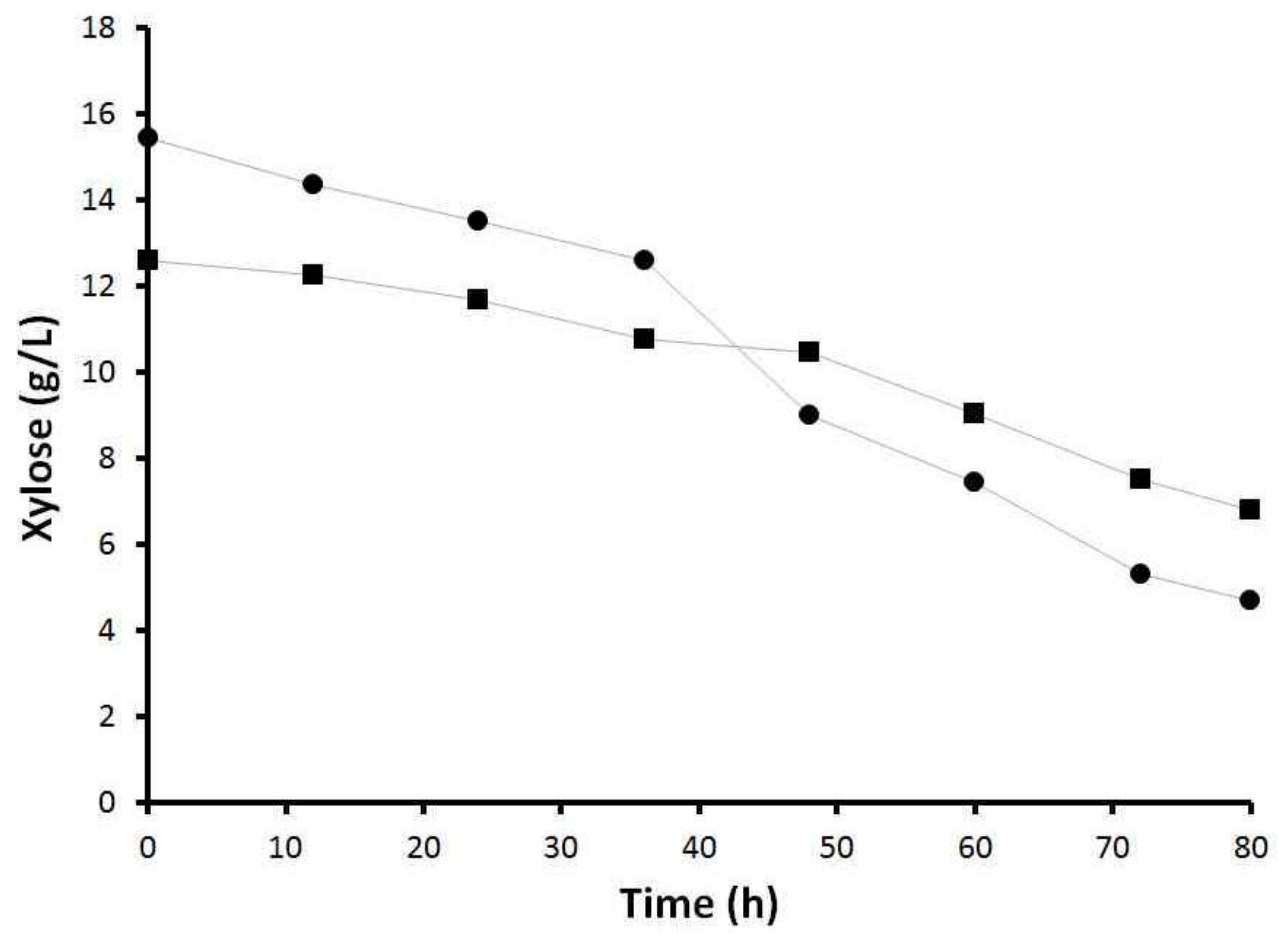

(A)

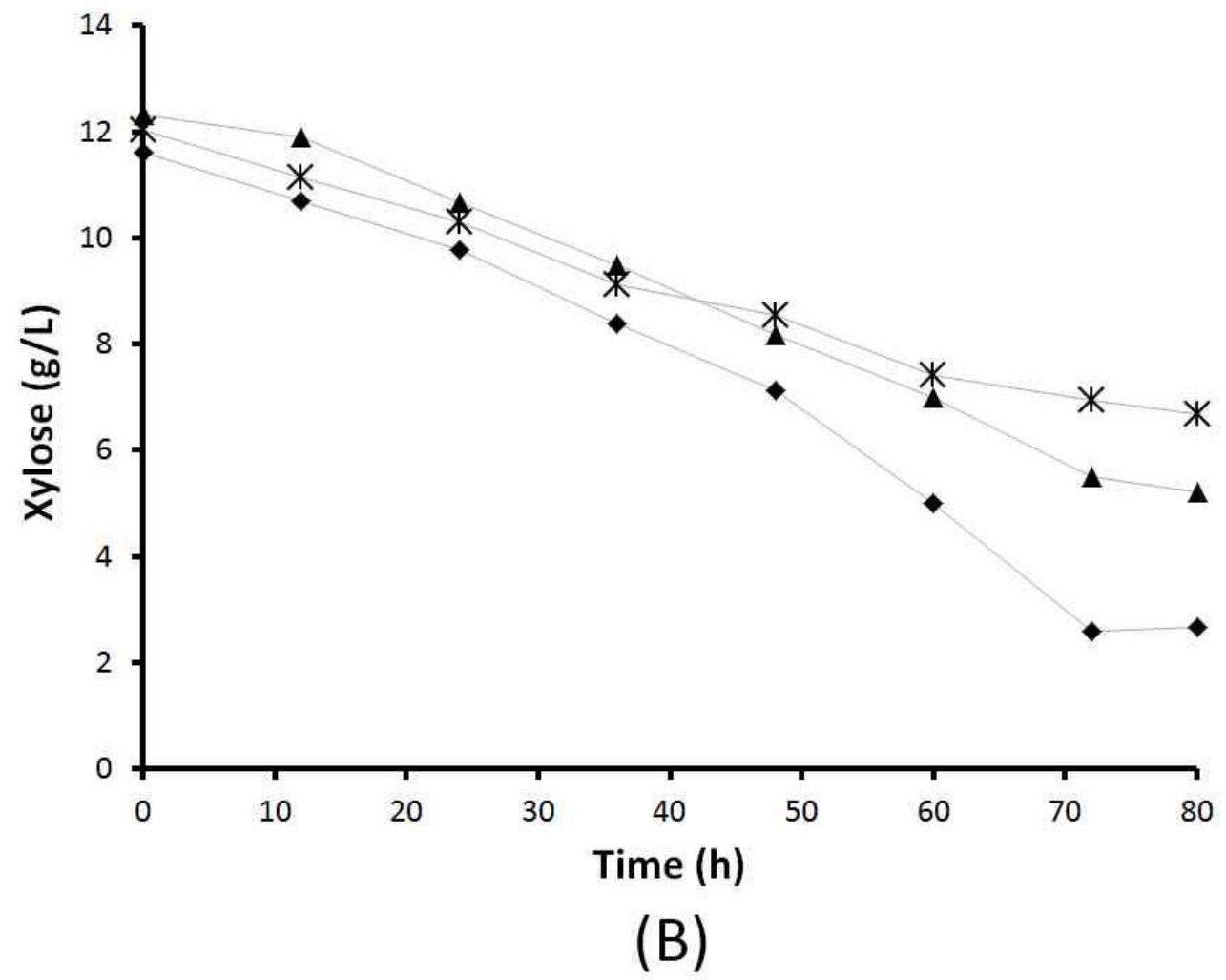


Fig.3 Xylitol production on the treatments of the factorial 22 experimental design with a central point. (A) Agitation of $100 \mathrm{rpm}$ and aeration of ( $\square$ ) $0.1 \mathrm{vvm},(\mathrm{O}) 1 \mathrm{vvm}$; (B) Agitation of $200 \mathrm{rpm}$ and aeration of $(\Delta) 0.1 \mathrm{vvm},(\diamond) 1 \mathrm{vvm}$ and $(ж) 0.55 \mathrm{vvm}, 150 \mathrm{rpm}$. Representative data for $\mathrm{n}=2$.

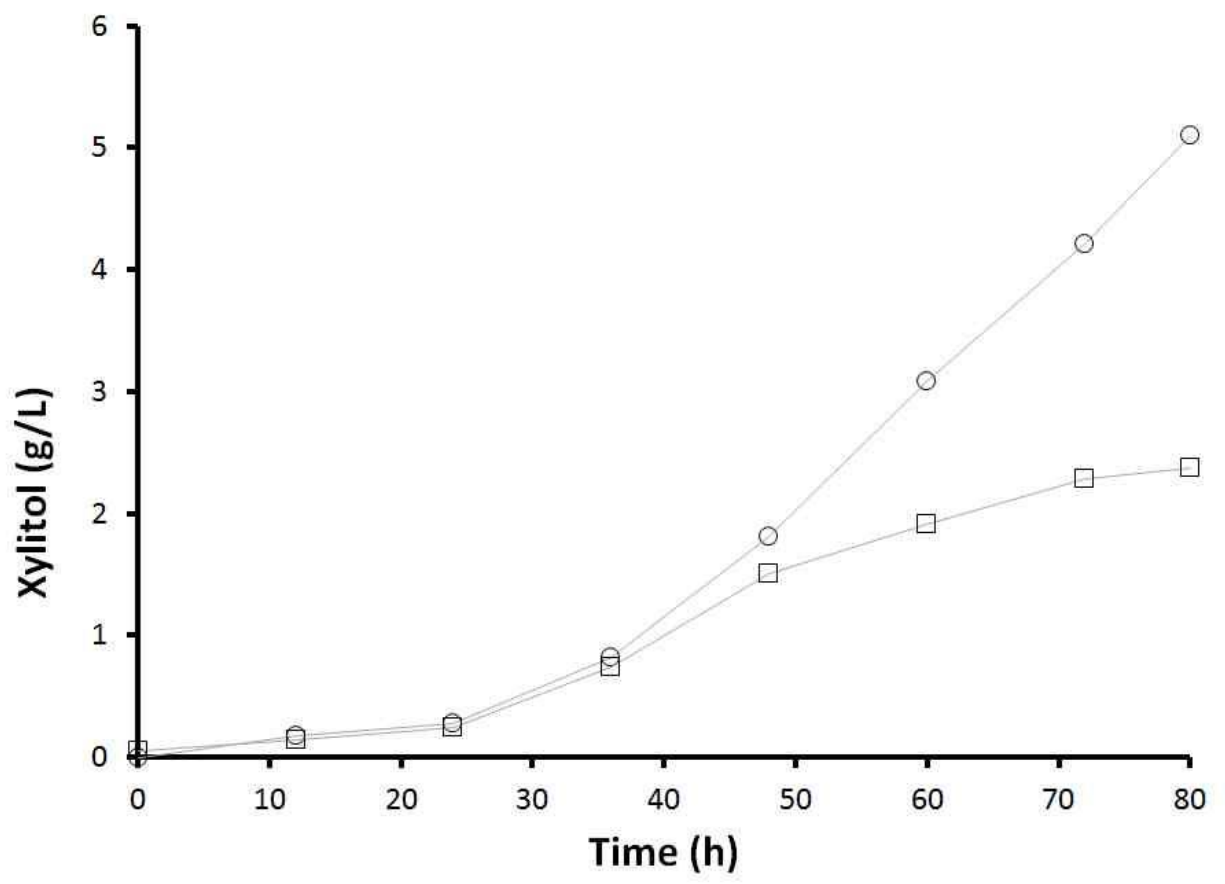

(A)

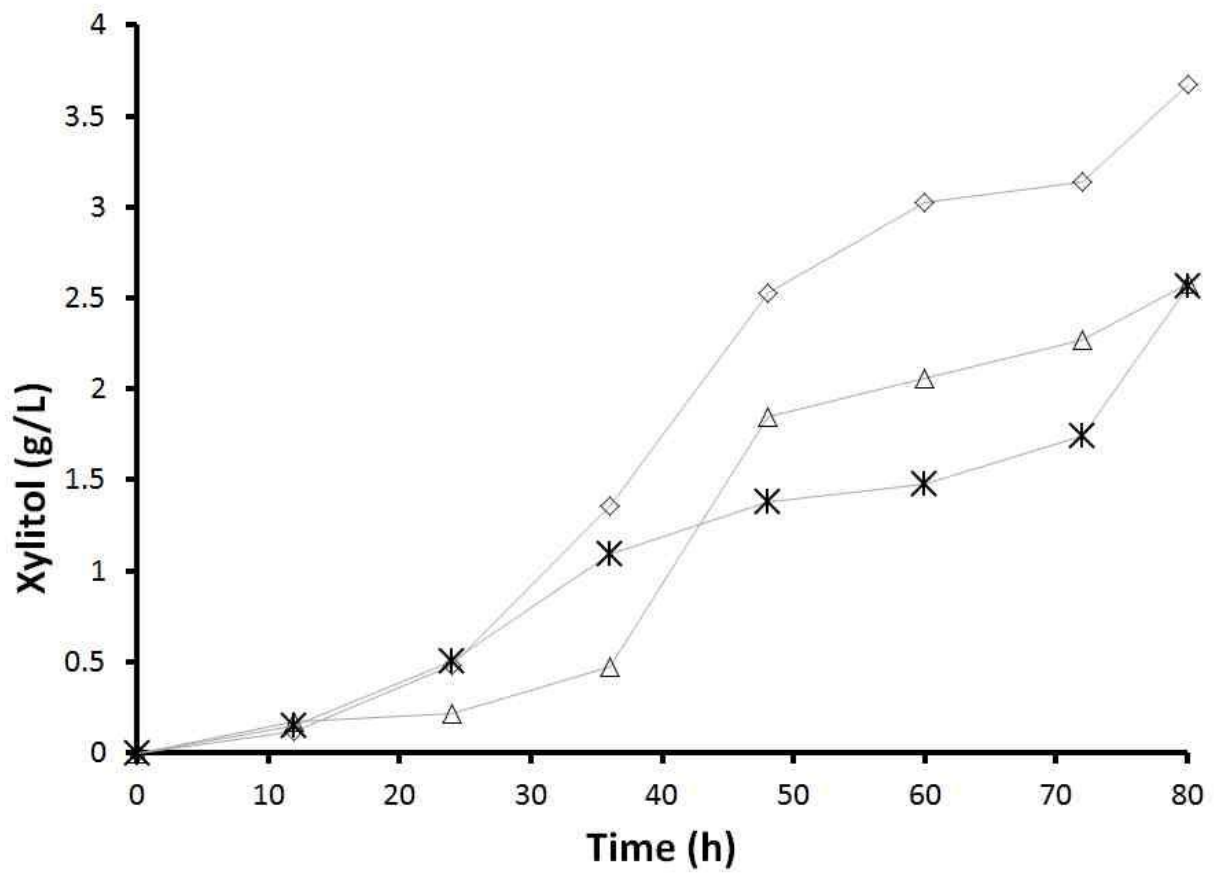

(B) 
Fig.4 Effects of the aeration and agitation on the product-substrate yield (Yp/s): (A) Principal effects of the factors and (B) interaction effect.
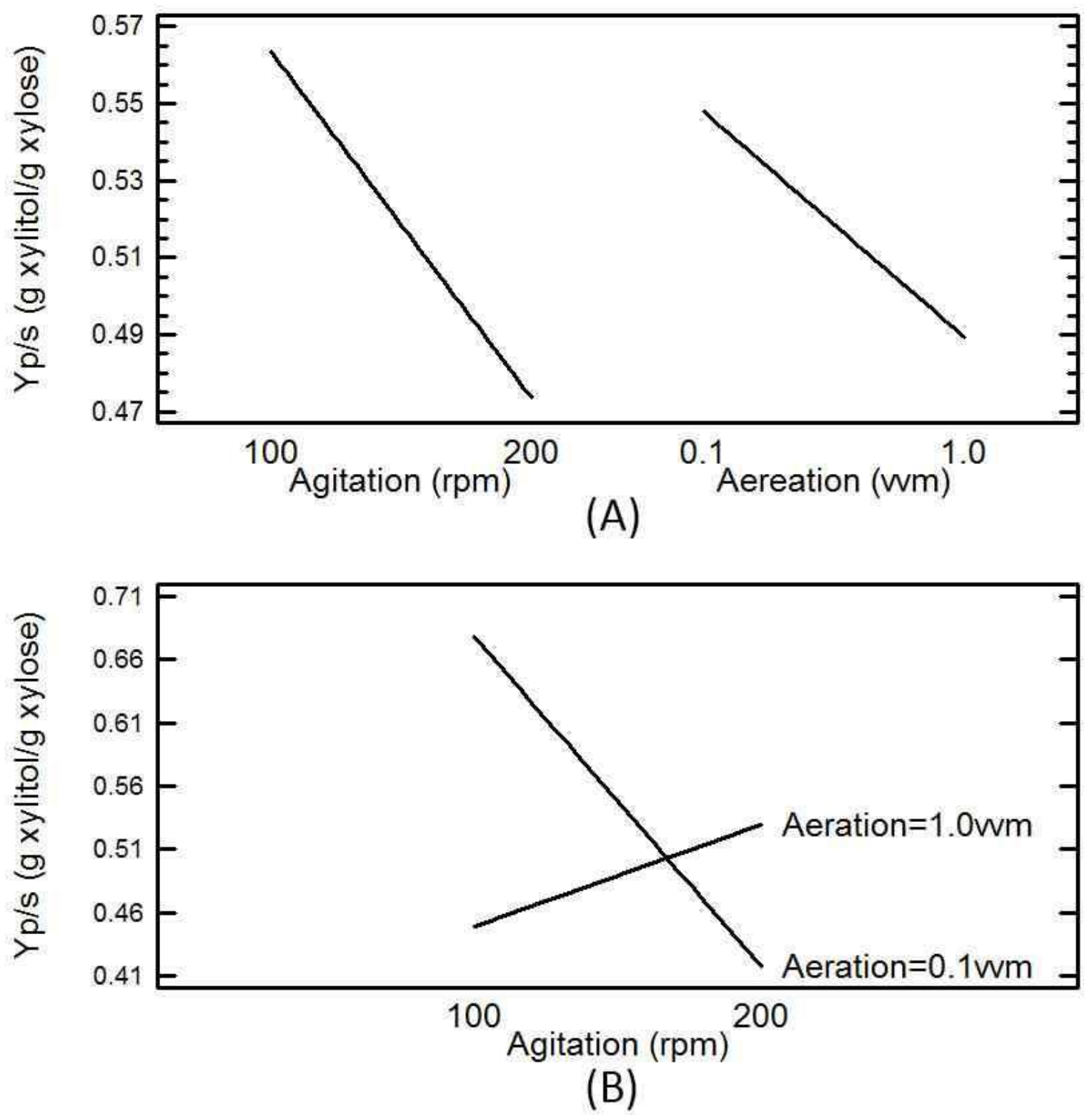
Fig.5 Effects of the aeration and agitation on the production of xylitol: (A) Principal effects of the factors and (B) interaction effect.

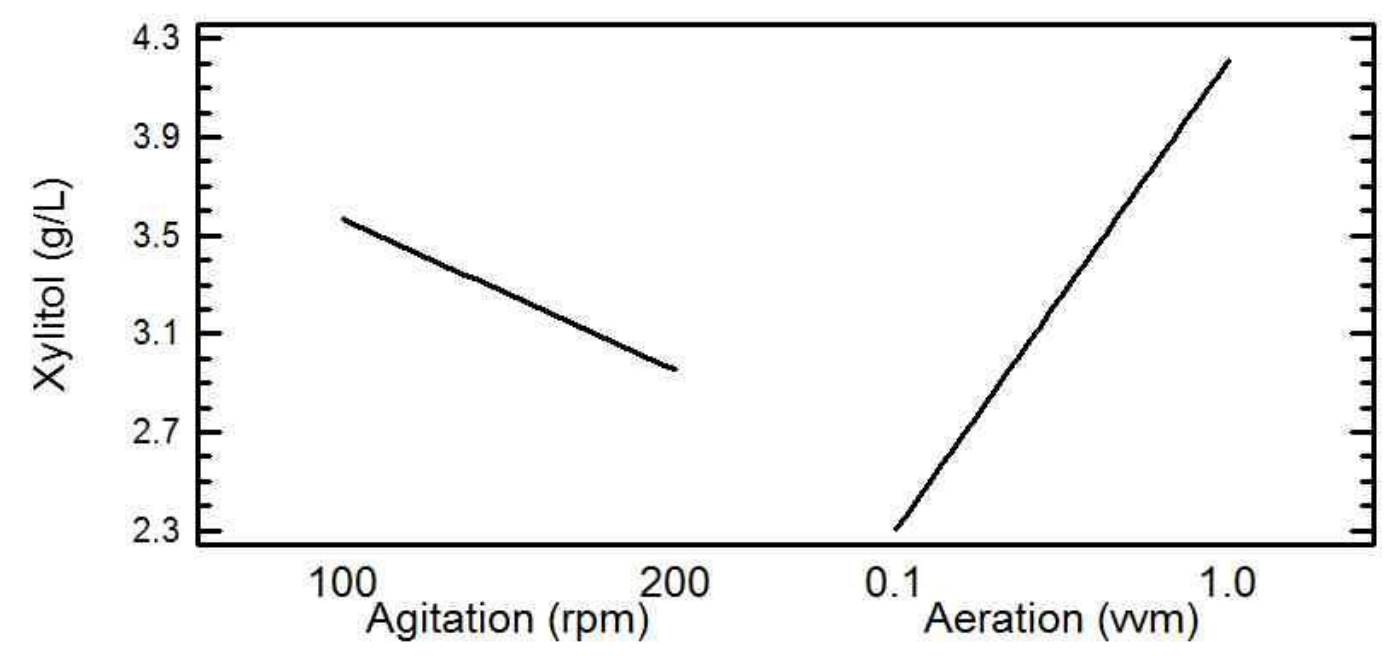

(A)

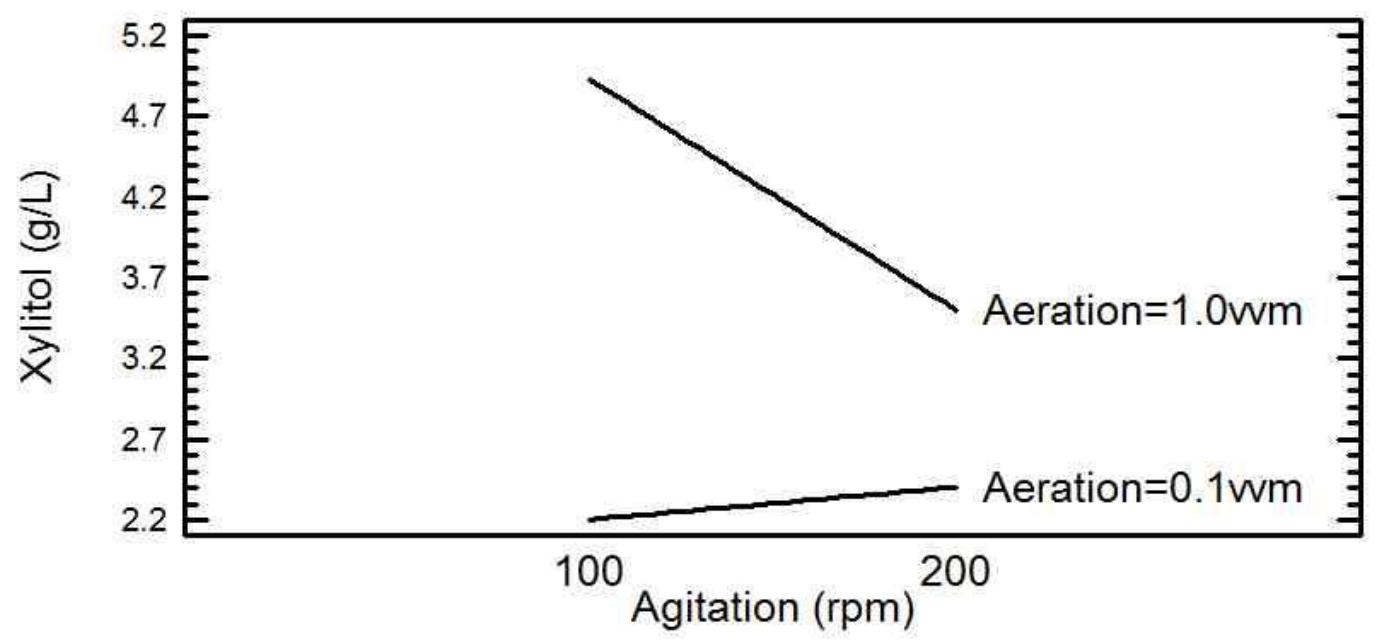

(B) 
Fig.6 Glucose consumption on the treatments of the factorial 22 experimental design with a central point. (A) Agitation of $100 \mathrm{rpm}$ and aeration of (घ) $0.1 \mathrm{vvm},(\bullet) 1 \mathrm{vvm}$; (B) Agitation of $200 \mathrm{rpm}$ and aeration of $(\boldsymbol{\Delta}) 0.1 \mathrm{vvm},(\diamond) 1 \mathrm{vvm}$ and (ж) $0.55 \mathrm{vvm}, 150 \mathrm{rpm}$. Representative data for $n=2$.

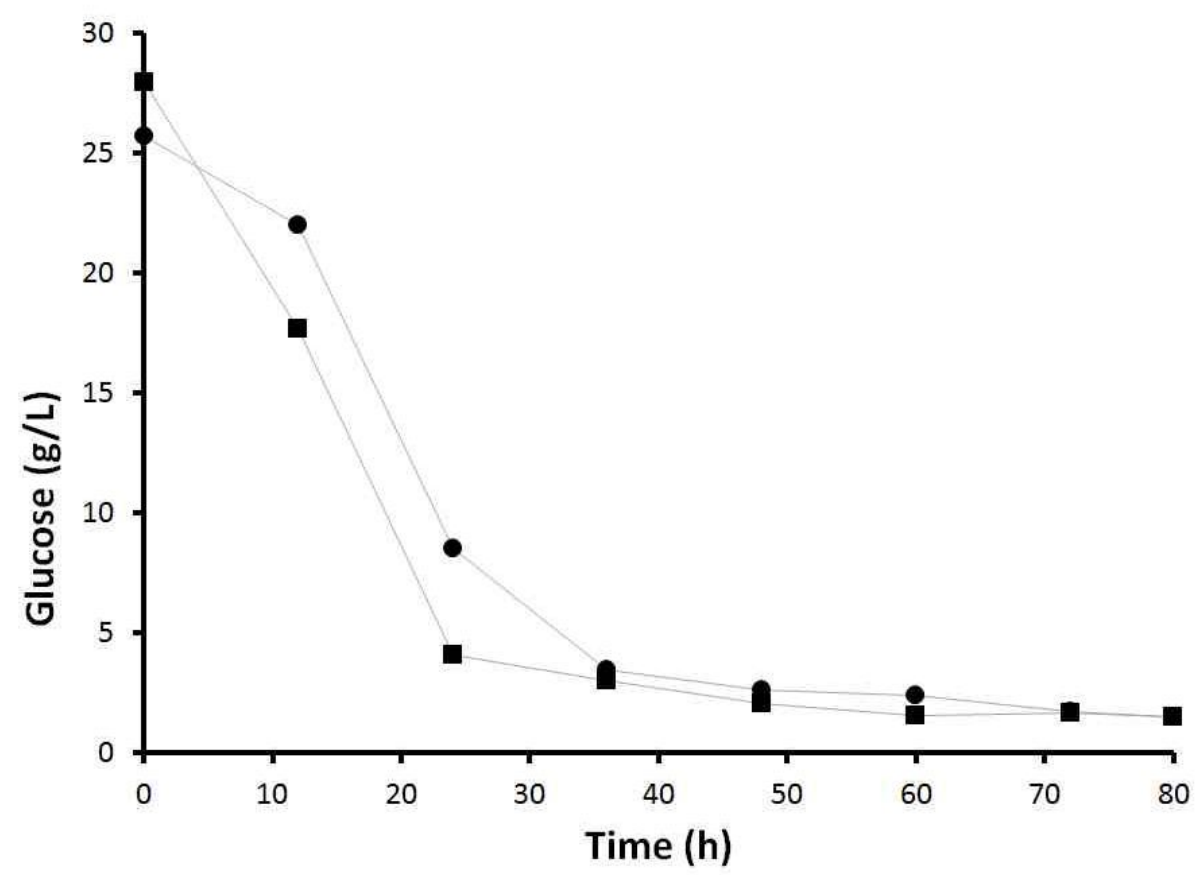

(A)

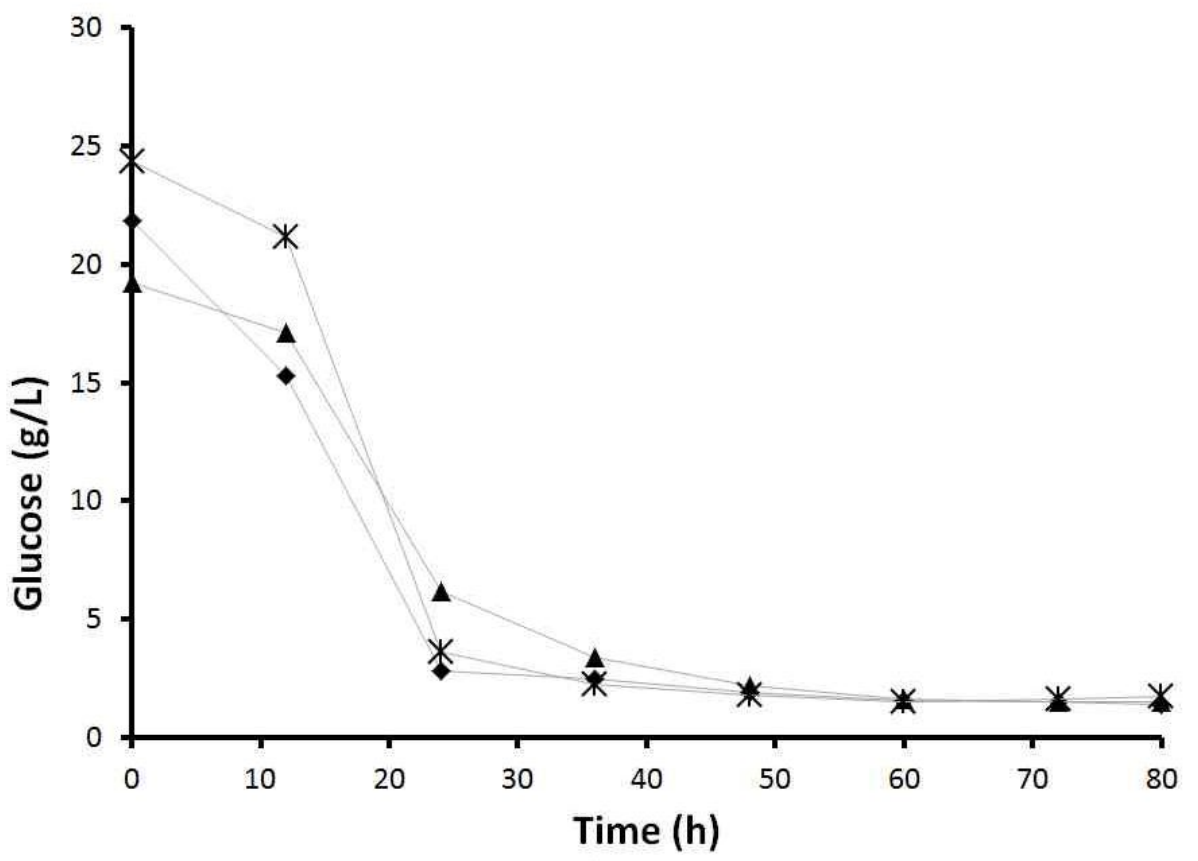

(B) 
Fig.7 Ethanol production on the treatments of the factorial 22 experimental design with a central point. (A) Agitation of $100 \mathrm{rpm}$ and aeration of (口) $0.1 \mathrm{vvm},(\mathrm{O}) 1 \mathrm{vvm}$; (B) Agitation of $200 \mathrm{rpm}$ and aeration of $(\Delta) 0.1 \mathrm{vvm},(\diamond) 1 \mathrm{vvm}$ and $(ж) 0.55 \mathrm{vvm}, 150 \mathrm{rpm}$. Representative data for $\mathrm{n}=2$.

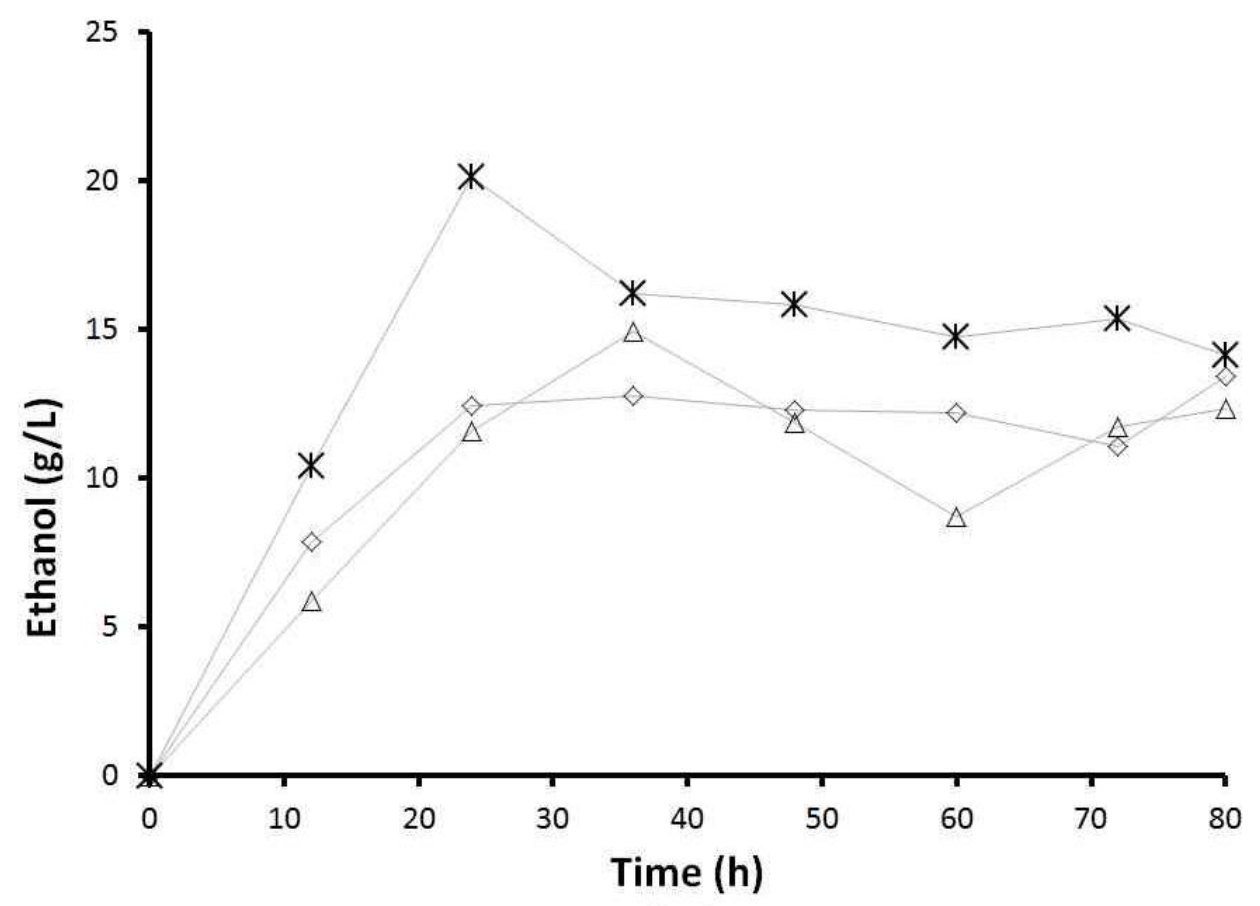

(A)

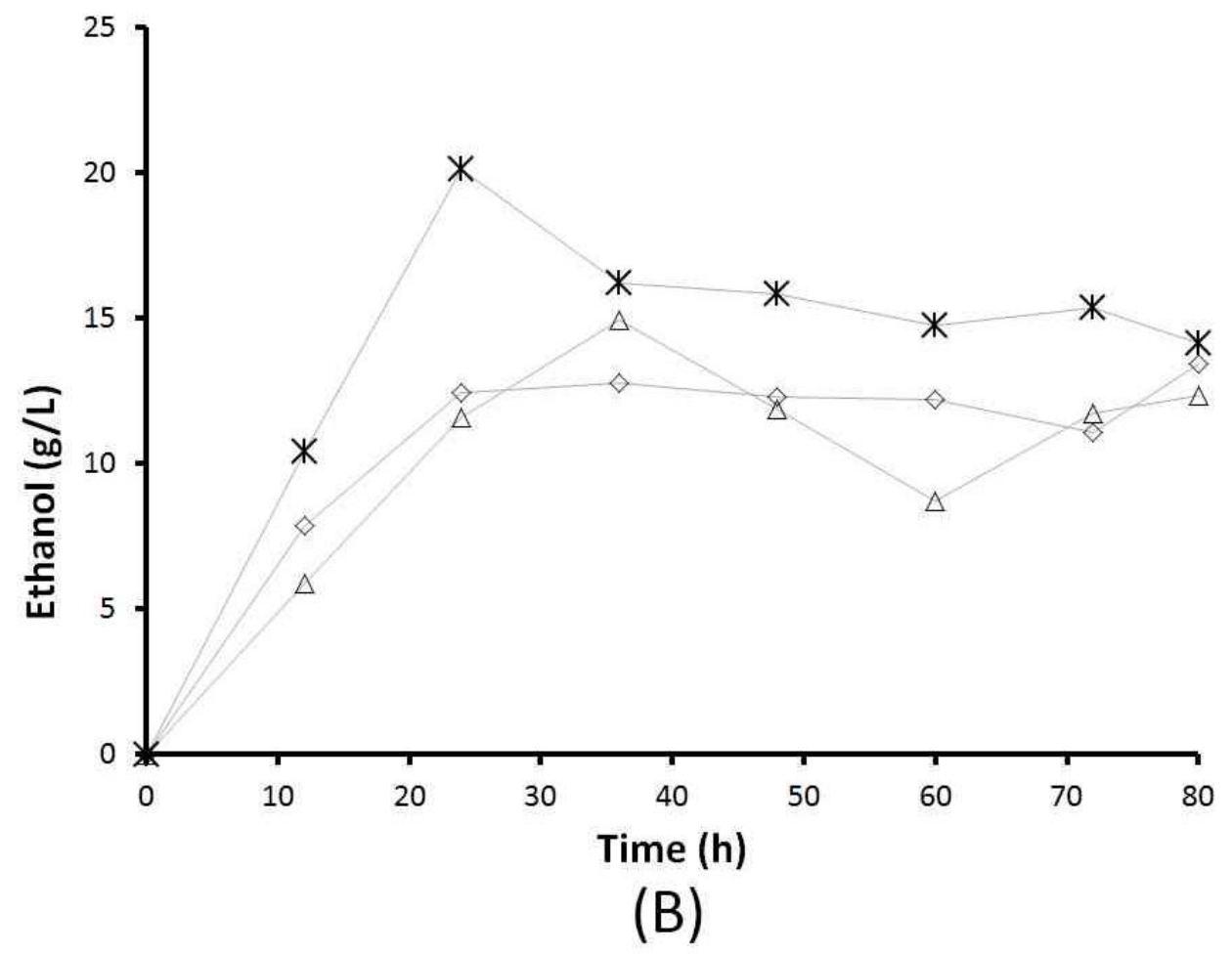


It was at the lowest levels of both factors (treatment 5) where the highest ethanol production was appreciated, according to the statistical analysis of the Tukey-Kramer test (Table 4). The rest of the treatments demonstrated lower ethanol production on finalizing the fermentation stage and do not differ statistically in a confidence level of 95 $\%$.

With reference to glycerol production: a greater concentration was obtained at low aeration levels, in treatments 2 and 5 (Table 4). In turn, treatment 5 does not differ statistically in glycerol production from the rest of the treatments, according to the Tukey-Kramer test. However, these results represent maximum glycerol concentrations during fermentation - where no specific tendencies can be observed (data not shown), therefore is difficult to predict the behavior of yeast respecting the generation of this product.

In conclusion, the concentration of furfurals, composites which have proved toxic for yeast and which inhibit xylitol production, in the hydrolyzed tamarind seed media $(0.214 \mathrm{~g} / \mathrm{L})$ did not have a lethal effect on $K$. marxianus. There was no inhibition in yeast growth in the conditions in which the treatments of the experimental design $2^{2}$ with a central point were carried out at bioreactor level. The effect of each factor (agitation and aeration) was low, but the interaction of both prevailing on yeast growth. The greatest adaptation (least doubling time) was observed at an agitation of $100 \mathrm{rpm}$ and an aeration of $1 \mathrm{vvm}$.

Neither did the principal factors affect product-substrate yield, but conversely the interaction between both did. The highest yield obtained was at the lowest levels of both (at $100 \mathrm{rpm}$ and $0.1 \mathrm{vvm}$ ), being $0.71 \mathrm{~g}$ of xylitol/g of xylose, in semi-anaerobic conditions. However, in this study, a high aeration level (1 vvm) benefited xylitol production; thereby, the presence of oxygen is of even greater importance, not only in yeast growth, but also in xylitol production during extended periods of time.

In this way, $K$. marxianus, a yeast of which little has been written with reference to its use in xylitol production, can be seen as a microorganism of both high productivity and yield for the production of this interesting metabolite, owing to its good adaptation level to a medium prepared from hydrolyzed tamarind seed.

\section{Acknowledgments}

We wish to thank CONACYT-CIENCIA BÁSICA (CB-2012-01., No.176199), PROMEP, IDCA 10761 (2012) for their partial financial support and the "Programa Institucional de Maestría en Ciencias Biológicas" (PIMCB) of the "Universidad Michoacana de San Nicolás de Hidalgo" through CONACYT Scholarship (Consejo Nacional de Ciencia y Tecnología) with registration number 388230 (Ricardo Martínez Corona).

\section{Conflict of Interest}

There is no conflict of interest.

\section{References}

Acosta, E., Batista de, A.J., Giulietti, M., Frade, J.A., Nápoles, A.I., Manganelly, E. 2005. Producción de xilitol en fermentador de 15 litros. Red de Revistas Científicas de América Latina, el Caribe, España y Portugal., 34: 45-51.

Ahmed, Z. 2001. Production of natural and rare pentoses using microorganisms 
and their enzymes. Electronic $J$. Biotechnol., 4: 1-9.

Almeida, J.R., Modig, T., Petersson, A., Hähn-Hägerdal, B., Lidén, G., Gorwa-Grauslund, M.F. 2007. Increased tolerance and conversion of inhibitors in lignocellulosic hydrolysates by Saccharomyces cerevisiae. J. Chem. Technol., 82: 340-349.

Arrizon, J., Mateos, J.C., Sandoval, G., Aguilar, B., Solís, J., Aguilar, M.G. 2011. Bioethanol and xylitol production from different lignocellulosic hydrolysates by secquential Fermentation. J. Food Process Engineering., 35: 437-454.

Bahador, A., Lesan, S., Kashi, N. 2012. Effect of xylitol on cariogenic and beneficial oral Streptococci: a randomized, double-blind crossover trial. Iranian J. Microbiol., 4: 75-81.

Boris, U.S., Mary, A.F., Arjun, S., Min, Z. 2003. D-Xylose transport by Candida succiphila and Kluyveromyces marxianus. Appl. Biochem. Biotechnol., 106: 255-263.

Deok-Kun, O., Sang-Yong, K., Jung-Hoe, K. 1997. Increase of xylitol production rate by controlling redox potential in Candida parapsilosis. Biotechnol. Bioengineering., 58: 440444.

Does, A.L., Bisson, L.F. 1989. Characterization of xylose uptake in the yeasts Pichia heedii and Pichia stipitis. Appl. Environ. Microbiol., 55: 159-164.

El-Siddig, K., Gunasena, H.P.M., Prasad, B.A., Pushpakumara, D.K.N.G., Ramana, K.V.R., Vijayanand, P., Williams, J.T. 2006. Tamarind Tamarindus indica. L. Southampton Centre for Underutilised Crops, Southampton, UK.
Fernández, T., Martin, C., Marcet, M., Thomsen, A.B. 2007. Fermentabilidad de prehidrolizados de residuos lignocelulósicos para la producción de etanol. Valoración de Residuos, Ingeniería Química., 455: 190-197.

Furlan, S.A., de Castro, H.F. 2001. Xylitol production by Candida parapsilosis under fed-batch culture. Brazilian Arch. Biol. Technol., 44: 125-128.

Ghindea, R., Csutak, O., Stoica, I., Tanase, A.M., Vassu, T. 2010. Production of xylitol by yeasts. Romanian Biotechnol. Lett., 15: 5217-5222.

González-Hernández, J.C., Farías, R.L., Vera, V.J.C., Martínez, C.R., Alvarez-Navarrete, M., Zamudio, J.M.A., Chávez, P.M.C., Peña, A. 2012. Chemical hydrolysis of the polysaccharides of the tamarind seed. J. Mexican Chem. Soc., 56: 395-401.

Granström, T. 2002. Biotechnological production of xylitol with Candida yeasts. Helsinki University of Technology, Department of Chemical Technology. Technical Report 2.

Hahn-Hägerdal, B., Fredrik, W.C., Gárdonyi, M.H. van Zyl W., Cordero, O.R.R., Jönsson, L.J. 2001. Metabolic engineering of Saccharomyces cerevisiae for xylose utilization. Adv. Biochem. Engi. Biotechnol., 73: 5384.

Kaur, G., Nagpal, A., Kaur, B. 2006. Tamarind. Sci. Tech. Entrepreneur.

Kiyoshi, T., Jun-Ichi, H., Tohru, K., Masayoshi, K. 2004. Microbial xylitol production from corn cobs using Candida magnoliae. J. Biosci. Bioengi., 98: 228-230.

Latina, C.F., Rubio, M.C., Navarro, A.R. 2006. Producción de xilitol a partir de xilosa extraída del hidrolizado de marlo de maíz. Instituto de Biotecnología - Facultad de 
Bioquímica, Química y Farmacia, Universidad Nacional de Tucumán. Tucumán, Argentina. Reporte Técnico.

Martínez, A., Rodríguez, M.E., York, S.W., Preston, J.F., Ingram, L.O. 2000. Use of UV absorbance to monitor furans in dilute acid hydrolysates of biomass. Biotechnol. Progress, 16: 637-641.

Martínez, E.A., Villarreal, L.M., Almeida e, S.J.B., Solenzal, A.I.N., Canilha, L., Mussatto, S.I. 2002. Uso de las diferentes materias primas para la producción biotecnológica de xilitol. Ciencia y Tecnología Alimentaria., 3: 295-301.

Martínez-Corona, R., González-Hernández, J.C., Zamudio-Jaramillo M.A., Cortés, P.C., Chávez, P.M.C. 2015. Effect of initial substrate concentration and agitation on xilitol production by fermentation of hydrolyzed tamarind seed media with Kluyveromyces marxianus. Revista Mexicana de Ingeniería Química., 14: 393-403.

Ojamo, H. 1994. Yeast xylose metabolism and xylitol production. Tesis para obtener el grado de Doctor, Universidad de Tecnología de Helsinki, Finlandia.

Palmqvist, E., Hahn-Hägerdal, B. 2000. Fermentation of lignocellulosic hydrolysates. II: Inhibitors and mechanisms of inhibition. Biores. Technol., 74: 25-33.

Pérez, E., González-Hernández, J. C., Chávez-Parga, M. C., CortésPenagos, C. 2013. Caracterización fermentativa de levaduras productoras de etanol a partir de jugo de Agave cupreata en la elaboración de mezcal. Revista Mexicana de Ingeniería Química., 12: 451-461.
Roberto, I.C., de Mancilha, I.M., Sato, S. 1999. Influence of $\mathrm{kLa}$ on bioconversion of rice straw hemicellulose hydrolysate to xylitol. Bioprocess Engi., 21: 505-508.

Santos, J.C., Carvalho, W., Silva, S.S., Converti, A. 2003. Xylitol production from sugarcane bagasse hydrolyzate in fluidized bed reactor. Effect of air flowrate. Biotechnol. Progress., 19: 1210-1215.

Saucedo-Luna, J., Castro-Montoya, A. J., Rico, J. L., Campos-García, J. 2010. Optimization of acid hydrolysis of bagasse from Agave tequilana Weber.

Revista Mexicana de Ingeniería Química., 9: 91-97.

Silva, C.J.S.M., Roberto, I.C. 2001. Improvement of xylitol production by Candida guilliermondii FTI 20037 previously adapted to rice straw hemicellulosic hydrolysate. Lett. Appl. Microbiol., 32: 248-252.

Skoog, K., Hahn-Hägerdal, B. 1990. Effect of oxygenation on xylose fermentation by Pichia stipitis. Appl. Environ. Microbiol., 56: 3389-3394.

Solange, I.M., Inês, C.R. 2005. Acid hydrolysis and fermentation of brewer's spent grain to produce xylitol. J. Sci. Food and Agri., 85: 2453-2460.

Taherzadeh, M.J., Gustafsson, J.L., Niklasson, C., Liden, G. 2000. Physiological effects of 5hydroxymethylfurfural on Saccharomyces cerevisiae. Appl. Microbiol. Biotechnol., 53: 701-708.

Vanegas, I.A., Yepes, M.S., Ruiz, O.S. 2004. Producción de xilitol a partir de levaduras nativas colombianas. Revista Colombiana de Biotecnología., 6: 31-36.

Villalba, C.M., Vélez, U.T., Arias, Z.M., Arrázola, P.G. 2009. Producción de xilitol a partir de cascarilla de arroz 
utilizando Candida guilliermondii. Revista Facultad Nacional de Agronomía, Medellín., 62: 48974905.

Wannawilai, S., Sirisansaneeyakul, S., Vanichsriratana, W., Prakulsuksatid, P. 2007. Optimization for the production of xylitol using Candida magnoliae TISTR 5663. TSB: A Solution to the Global Economic Crisis.
Weusthuis, R.A., Pronk, J.T., van den Broek, P.J., van Dijken, J.P. 1994. Chemostat cultivation as a tool for studies on sugar transport in yeasts. Microbiol. Rev., 58: 616-630.

Winkelhausen, E., Amartey, S.A., Kuzmanova, S. 2004. Xylitol production from $\mathrm{D}$-xylose at different oxygen transfer coefficients in a batch bioreactor. Engi. Life Sci., 4: 150154.

\section{How to cite this article:}

Ricardo Martínez-Corona, Carlos Cortés Penagos, María del Carmen Chávez-Parga, Mariana Alvarez-Navarrete and Juan Carlos González-Hernández. 2016. Analysis of the Effect of Agitation and Aeration on Xylitol Production by Fermentation in Bioreactor with Kluyveromyces marxianus Using Hydrolized Tamarind Seed as Substrate. Int.J.Curr.Microbiol.App.Sci. 5(6): 479-499.

doi: http://dx.doi.org/10.20546/ijcmas.2016.506.055 